\title{
Rainfall and Cloud Dynamics in the Andes: A Southern Ecuador Case Study
}

\author{
Lenin Campozano, ${ }^{1,2,3}$ Rolando Célleri, ${ }^{1,4}$ Katja Trachte, ${ }^{3}$ \\ Joerg Bendix, ${ }^{3}$ and Esteban Samaniego ${ }^{1,2}$ \\ ${ }^{1}$ Departamento de Recursos Hídricos y Ciencias Ambientales, Universidad de Cuenca, 10150 Cuenca, Ecuador \\ ${ }^{2}$ Facultad de Ingeniería, Universidad de Cuenca, Avenida 12 de Abril s/n, 10150 Cuenca, Ecuador \\ ${ }^{3}$ Laboratory for Climatology and Remote Sensing (LCRS), Faculty of Geography, University of Marburg, Deutschhausstraße 10, \\ 35032 Marburg, Germany \\ ${ }^{4}$ Facultad de Ciencias Agropecuarias, Universidad de Cuenca, Avenida 12 de Abril s/n, 10150 Cuenca, Ecuador
}

Correspondence should be addressed to Lenin Campozano; lenin.campozano@ucuenca.edu.ec

Received 11 November 2015; Revised 19 December 2015; Accepted 20 December 2015

Academic Editor: Charles Jones

Copyright (C) 2016 Lenin Campozano et al. This is an open access article distributed under the Creative Commons Attribution License, which permits unrestricted use, distribution, and reproduction in any medium, provided the original work is properly cited.

\begin{abstract}
Mountain regions worldwide present a pronounced spatiotemporal precipitation variability, which added to scarce monitoring networks limits our understanding of the generation processes involved. To improve our understanding of clouds and precipitation dynamics and cross-scale generation processes in mountain regions, we analyzed spatiotemporal rainfall patterns using satellite cloud products (SCP) in the Paute basin (900-4200 m a.s.l. and $\left.6481 \mathrm{~km}^{2}\right)$ in the Andes of Ecuador. Precipitation models, using SCP and GIS data, reveal the spatial extension of three regimes: a three-modal (TM) regime present across the basin, a bimodal (BM) regime, along sheltered valleys, and a unimodal (UM) regime at windward slopes of the eastern cordillera. Subsequently, the spatiotemporal analysis using synoptic information shows that the dry season of the BM regime during boreal summer is caused by strong subsidence inhibiting convective clouds formation. Meanwhile, in UM regions, low advective shallow cap clouds mainly cause precipitation, influenced by water vapor from the Amazon and enhanced easterlies during boreal summer. TM regions are transition zones from UM to BM and zones on the windward slopes of the western cordillera. These results highlight the suitability of satellite and GIS data-driven statistical models to study spatiotemporal rainfall seasonality and generation processes in complex terrain, as the Andes.
\end{abstract}

\section{Introduction}

Mountain regions provide diverse resources and services worldwide. Of especial importance is the provision of water for several uses like irrigation and drinking water [1]. However, the assessment of water resources in mountain regions is uncertain due to the combination of high spatiotemporal precipitation variability and scarce monitoring networks. These also hinder the understanding of the precipitation processes. In particular the Andes represent a privileged region for studying the processes involved in clouds formation and rainfall development [2].

The Andes cordillera, in Ecuador, is oriented from north to south and is formed by two mountain ranges, which are sharply pronounced in the northern and central part and hardly established in the southernmost part of the country [3]. The Andes cordillera acts as a weather divide in Ecuador [4]. Towards the west of the cordillera, in the coastal plains, one rainy season occurs from December to April, which is mainly modulated by the Pacific Ocean sea surface influence, especially by the region Nino $1+2$, and by the evolution of the intertropical convergence zone (ITCZ). In the Amazon, towards the eastern part of the Andes, the rainfall is present year-around, with two periods of higher rainfall during March-May and October-November, modulated by the ITCZ and moist air from the Amazon basin. The inter-Andean valleys between the two mountain ranges present a bimodal regime of rainfall, with a dry period during boreal summer. 
The wind field in the eastern Andes is generally characterized by a very high frequency of easterlies (75\%) all year-around [5], and the east facing slopes without shelter are frequently exposed to the main air stream. These climatic influences added to the complex topography of the Andes make their study scientifically important and challenging.

Nonetheless, there are some studies that deal with the characterization of rainfall dynamics in this region. For instance, in the Paute basin $\left(\mathrm{PB}, 6481 \mathrm{~km}^{2}\right)$ in the Southern Andes of Ecuador, [6] used 35 stations to study the annual precipitation variability, identifying 7 homogeneous regions. Not all subcatchments could be considered because of a lack of data. The work in [7] analyzed 23 rainfall stations to study the spatial variability of annual rainfall and the relation of precipitation and altitude as well as intraseasonal rainfall variability/trends for 11 stations with longer time series. They identified two main annual rainfall regimes in space, a bimodal (BM) and a unimodal (UM) type, including subtypes BM1, the inter-Andean valley stations, with a marked dry season during JJA and BM2, a high mountain regime with higher amounts of annual precipitation. Because no spatial precipitation information was available, delineation of the regions was conducted by using a digital terrain model. With respect to the dependence of precipitation on elevation they could not find a clear relation. The work in [8] studied spatial and temporal rainfall patterns in the west part of the PB (3500-4100 $\mathrm{m}$ a.s.l.) using 14 stations installed from 2001 to 2005. They found that only stations within $4 \mathrm{~km}$ distance are strongly correlated. Also they found that seasonal variation was low, around $100 \mathrm{~mm}$ between the wettest and the driest month. With respect to the relation between average daily rainfall and orographic features as slope and aspect, significant correlations were found. For interannual precipitation variability, the Rio Paute system is also influenced by quasiperiodic oscillations of the ENSO system [9]. Therefore, [10] studied decadal oscillations on time series of monthly precipitation (25 stations) and temperature (16 stations). They found that rainfall variations were negatively correlated with the sea surface temperature anomalies of El Nino $1+2$ region. The stations from the BM2 region with a northeast aspect showed strong anomalies in similar periods as Amazon regime stations. BM1 stations revealed similar behavior with lower correlation to large-scale circulation. These facts highlight the influence of orographic features on the rainfall spatial distribution. Therefore, depending on the climatic influences, orography complexity, and data accessibility, the instauration of adequate monitoring networks to properly understand rainfall distribution and generation processes may be difficult and sometimes impossible.

The lack of adequate monitoring networks for studying such rainfall variability makes the use of remotely sensed data and/or regional climate modeling necessary. With reference to a specific mountain region in the Andes of southern Ecuador, [11] investigated cloud frequency, cloud top height, and cloud liquid water path using a data set of NOAAAVHRR (NOAA-Advanced Very High Resolution Radiometer) imagery in $1 \mathrm{~km}$ resolution. In general they found that the seasonal cycle of cloudiness is significantly correlated to the spatial occurrence of the rainy seasons. However, the complex topography of the Andes, with dynamic effects at the windward and lee sides, as well as thermal breezesystems, causes a specific spatial structure of cloud frequency and cloud properties. Regarding rainfall, [12] evaluated a big data set of surface precipitation stations against data from the Tropical Rainfall Measuring Mission (TRMM) 3B42 V7 and its predecessor V6, as well as the North Western South America Retrospective Simulation (OA-NOSA30), covering 21 subcatchments situated in the westernmost axis of South America, the Pacific-Andean basin into Ecuador and Peru. They found that only the southern subcatchments of Ecuador and northern Peru were relatively well estimated by both methods. However, the accuracy of both approaches was quite poor in the northern and central basins in the region of study (0-3.6 S), limiting the possibility of its use. Particularly the model based OA-NOSA30 was inferior in generating the spatial distribution of the mean annual precipitation. Considering regional climate modeling, [13] aimed at reproducing temperature and rainfall seasonality for 3 stations in the PB and 2 stations in the Jubones basin, located towards the south. Although the seasonal patterns were represented, improving those of reanalysis data, however monthly amounts were strongly overestimated. Finally, the uncertainties in climate change projections as derived by climate models for the Andes of Ecuador and the Paute system are shown to be enormous. For instance, for precipitation, climate models differ considerably in the region of study: some models project positive anomalies while others project negative anomalies [14]. This is due, in part, to climate models nonadapted to the complex topography which is required to resolve rainfall formation processes across different scales [15-18]. In addition, climate models need observational data to be adequately calibrated, which, in the case of the PB, is still required.

In summary, different rainfall regimes exist in the Rio Paute catchment area, but to date a spatial explicit delineation is still lacking due to the scarcity of the station network. Furthermore, no study hitherto exists that links the zonation to potential rainfall generation processes and the varying influences ranging from global circulation patterns to mesoscale atmospheric processes, which might be responsible for rainfall formation in time and space. Hence, the main aim of the present study is to understand the spatiotemporal dynamics of precipitation and clouds, as well as the potential cross-scale generation processes of rainfall in the Paute basin. In Section 2, the study area and data are presented. Section 3 describes the methods used in this study, while Section 4 introduces the results and discussion. Finally, Section 5 presents a summary, which is followed by the conclusions in Section 6.

\section{Study Area and Data}

The study region is the Paute river basin (Figure 1), $6481 \mathrm{~km}^{2}$. The Paute basin is located in the inter-Andean depression between the western and the eastern Andean escarpments of southern Ecuador [3]. Its elevation range varies from 900 to $4200 \mathrm{~m}$ a.s.l. and around $40 \%$ of the basin is covered by páramo [7]. The páramo is a neotropical alpine wetland ecosystem covering the upper Andean region of Venezuela, 


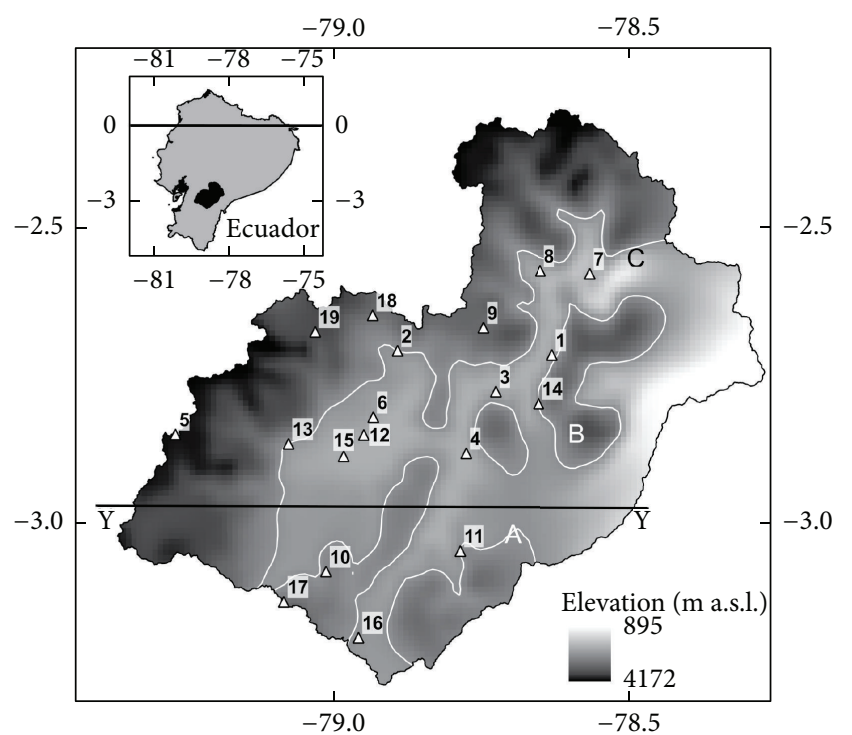

$\Delta \quad$ Rainfall stations

$2700 \mathrm{~m}$ a.s.l.

Figure 1: The Paute river basin in south Ecuador. Profile Y-Y black line. Prominent orographic features are Mount El Calvario (A), Mount Bellavista (B), and Paute canyon (C).

Colombia, Ecuador, and Peru [19]. Ecosystem services provided by the páramo include high water regulation capacity and carbon sequestration. Particularly, several cities along the Andes like Quito and Bogotá [20] and irrigation systems [20] benefit from water yielded from the páramo. Its high water regulation capacity [21] originates from a combination of its soil properties (mainly Andosols and Histosols, with high organic matter content) that can store large volumes of water [22], the climate (rainy, cold, and cloudy) [23, 24], and the vegetation (mainly tussock grasses and cushion plants). Predicted changes in the climate will lead to negative changes in its water regulation [25] and therefore they are considered a very fragile component of the high Andean ecosystems. The Paute river basin feeds several hydroelectric power plants, Amaluza (1075 MW), El Labrado y Chanlud (38.4 MW), Mazar (162.6 MW), and Sopladora (500 MW), generating around $40 \%$ of the Ecuadorian national hydroelectrical production. Several cities in the region depend directly on diverse hydroecological services of the basin.

The topography shows main ridges of the Andean western cordillera bordering the basin to the south and east. Two lower ridge systems are striking SW-NE, separated by river valleys as the one of the Rio Paute. The lowest part in the northeast marks the outflow of the river system toward the Amazon lowlands. The eastern part of the Paute basin is located on the escarpments of the eastern cordillera. In this region the Paute basin is influenced by the Andean Occurring System (AOS), which is a band of clouds and rain located along the eastern escarpments of the eastern cordillera.

Data from 15 rainfall stations of the Ecuadorian National Institute of Meteorology and Hydrology, INAMHI, delivering daily values for the period from January 2000 to December
2009 were available (Table 1). Data from 4 rainfall stations of the Empresa Municipal de Telecomunicaciones, Agua Potable y Saneamiento, ETAPA, delivering hourly values for the period from December 2001 to December 2009 were also available (Table 1). For the quality control of the data, time series with less than $10 \%$ of gaps during the study period was considered in first place. Then homogeneity was checked with the package RHTestsV3 $[26,27]$ on monthly data, since daily time series can be very noisy. The software change point detection test is based on the penalized maximal $F$ test. Finally infilling of gaps in homogeneous time series was conducted using a multiple regression model with the stations of higher correlation [28].

The satellite products used in this study are based on 452 NOAA-AVHRR scenes acquired during 2002 and 2004. The data set has a spatial resolution of $1 \mathrm{~km}$ and consists of cloud frequency (CF), cloud top height (ZMIT), and cloud liquid water path (LWP). For more details on the generation of the data set the reader may refer to $[29,30]$. For elevation terrain information the Global 30 Arc-Second Elevation (GTOPO30) was used (Data available from the U.S. Geological Survey). Also, reanalysis data from 1981 to 2010 period was used. Omega, zonal wind, meridional wind, and specific humidity from NCEP/NCAR 40-year reanalysis 1 project were used [31].

\section{Methods}

To improve our understanding of spatiotemporal dynamics of precipitation and clouds, as well as the potential crossscale generation processes of rainfall in the Paute basin, the present study was conducted in two stages. First, we pursue the delineation of precipitation regimes across the basin, based on cloud products and GIS data. We considered that the identification of precipitation regimes by regions might help to differentiate influences in precipitation at synoptic, meso-, and local scales. Secondly, we analyzed the rainfall dynamics and the relation to cloud dynamics and orography using reanalysis data and cloud products to understand further the synoptic conditions influencing precipitation in the PB.

3.1. Spatial Delineation of Rainfall Seasonality. The work flow for spatial data set generation of seasonality is presented in Figure 2. The approach consists of five consecutive steps including (i) generation of normalized precipitation regimes (NPRs), (ii) area-wide seasonal delineation using satellite derived variables CF, LWP, and ZMIT, (iii) the development of a model of rainfall based on principal component analysis (PCA) applied to CF (CFM) to generate seasonality delineation, (iv) the development of a multiple linear regression model (MLRM) of rainfall to generate seasonality delineation, and (v) the pixel-wise evaluation of regionalization obtained from CF, LWP, ZMIT, CFM, and MLRM against zonation from [7]. Kendall's tau correlation is a robust nonparametric estimate of similarity between two ranked series. Therefore, no a priory assumption about the distribution is necessary. Because NPRs and CF, LWP, ZMIT, MLRM, and CFM exhibit non-Gaussian asymmetric distributions, 
TABLE 1: Precipitation stations of the Paute river basin. INAMHI (Instituto Nacional de Meteorología e Hidrología) stations with daily data and ETAPA (Empresa Pública Municipal de Teléfonos, Agua Potable y Alcantarillado de Cuenca) with hourly data. * Stations used for validation of rainfall models.

\begin{tabular}{|c|c|c|c|c|c|c|}
\hline$\#$ & Code & Name & Lat (deg.) & Log (deg.) & Altitude (m a.s.l.) & Institution \\
\hline 1 & M045 & Palmas & -2.716 & -78.63 & 2400 & INAMHI \\
\hline 2 & M137 & Biblian & -2.709 & -78.892 & 2640 & INAMHI \\
\hline 3 & M138 & Paute & -2.778 & -78.726 & 2289 & INAMHI \\
\hline 4 & M139 & Gualaceo & -2.882 & -78.776 & 2360 & INAMHI \\
\hline 5 & M141 & El Labrado & -2.85 & -79.267 & 3260 & INAMHI \\
\hline 6 & M197 & Jacarin & -2.821 & -78.933 & 2700 & INAMHI \\
\hline 7 & M217 & Peñas Coloradas & -2.579 & -78.566 & 2000 & INAMHI \\
\hline 8 & M410 & Mazar Rivera & -2.574 & -78.65 & 2450 & INAMHI \\
\hline 9 & M414 & Chanin & -2.67 & -78.747 & 3020 & INAMHI \\
\hline 10 & M418 & Cumbe & -3.083 & -79.0128 & 2720 & INAMHI \\
\hline 11 & M424 & Sigsig Inamhi & -3.048 & -78.786 & 2600 & INAMHI \\
\hline 12 & M426 & Ricaurte & -2.851 & -78.949 & 2545 & INAMHI \\
\hline 13 & M427 & Sayausi & -2.866 & -79.076 & 2710 & INAMHI \\
\hline 14 & M431 & Sevilla de Oro & -2.798 & -78.653 & 2360 & INAMHI \\
\hline 15 & M067 & Cuenca Aeropuerto* & -2.887 & -78.983 & 2516 & INAMHI \\
\hline 16 & - & Jima* & -3.194 & -78.958 & 2898 & ETAPA \\
\hline 17 & - & Portete ${ }^{*}$ & -3.134 & -79.084 & 3174 & ETAPA \\
\hline 18 & - & La Esmeralda* & -2.649 & -78.934 & 3171 & ETAPA \\
\hline 19 & - & Chanlud* & -2.677 & -79.031 & 3485 & ETAPA \\
\hline
\end{tabular}

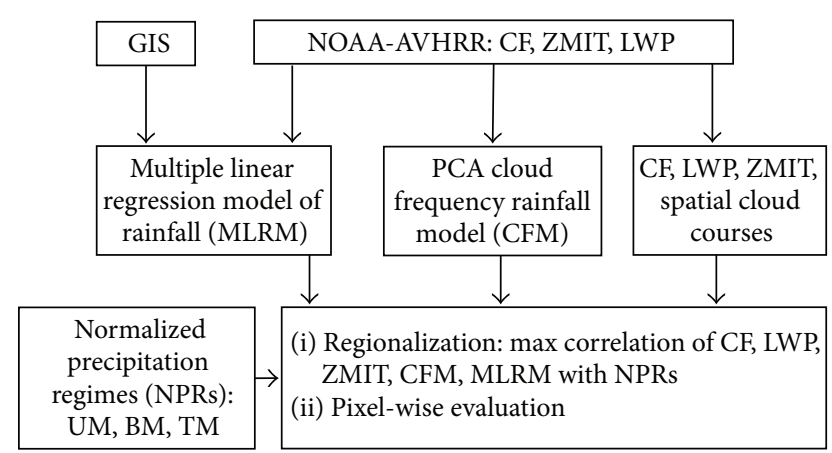

FIGURE 2: Overall work flow of spatial data set generation of seasonality.

Kendall's tau correlation was calculated and tested at 0.05 significance level. The relation between rainfall and the variables used from cloud products is complex. Therefore detecting at least low linear correlations between them is important. Thus, to represent the seasonal delineation, the evaluation of the maximum Kendall's tau correlation greater than 0.3 comparing the three NPRs with CF, LWP, ZMIT, MLRM, and CFM was conducted. In the following paragraphs these steps will be explained.

3.1.1. Normalized Precipitation Regimes (NPRs). Stations with similar seasonality were grouped to obtain a representative pattern for each type of precipitation regime. Following $[4,7]$, three seasonal rainfall regimes are present in the Paute river basin (Figure 3), BM, UM, and three-modal (TM) regime. While the BM regime is the typical high inter-Andean type,
TM regime is a high mountain regime with higher amounts of annual precipitation. In order to classify monthly precipitation by signal, three normalized precipitation regimes (NPRs) as shown in Figure 3 are defined. The normalization of precipitation was calculated dividing the average monthly precipitation from all stations of the respective regime (UM, $\mathrm{BM}$, or $\mathrm{TM}$ ) by the average maximum monthly precipitation occurring in the seasonal regime.

\subsubsection{Types of Area-Wide Seasonal Regimens Using Satellite} Derived Variables. From a conceptual consideration, three variables derived from satellite data are expected to be related to monthly rainfall [32]: monthly CF, average LWP, and mean ZMIT. It is expected that (i) the higher the cloud frequency in one grid cell, the higher the likelihood for rainfall (e.g., blurred by nonraining low clouds), (ii) the greater the cloud top height, the higher the likelihood for convective precipitation (e.g., blurred by strong cloud advection), and (iii) the greater the liquid water path, the greater the likelihood for big droplets forming rainfall [32]. For the assessment of the satellite data set, a pixel-wise calculation of Kendall tau correlation and significance between the UM, BM, and TM NPRs and the space-borne variable is conducted.

3.1.3. PCA Cloud Frequency Model of Rainfall. The rainfall model based on the application of PCA to monthly cloud frequency (CFM) uses the 3 main principal components as inputs and the monthly rainfall as output. These components were selected after the application of the scree test. The scores from the first 3 PCs are the three main CF patterns, and their occurrence through the 12 months is represented by 


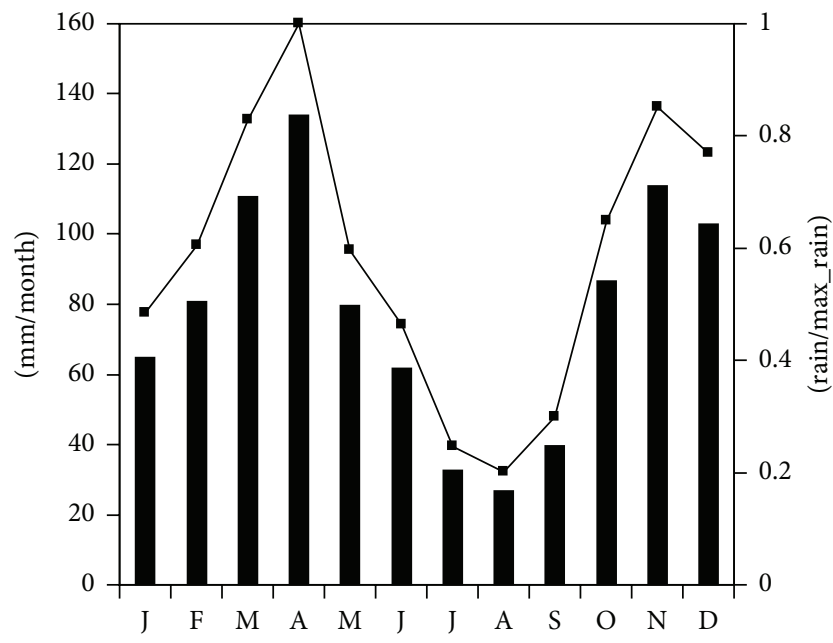

(a) BM

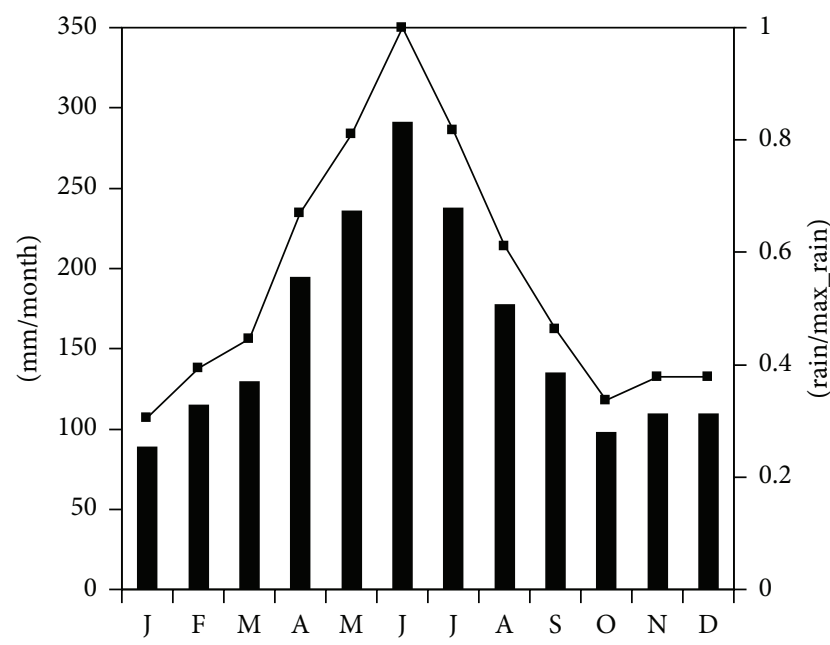

(b) UM

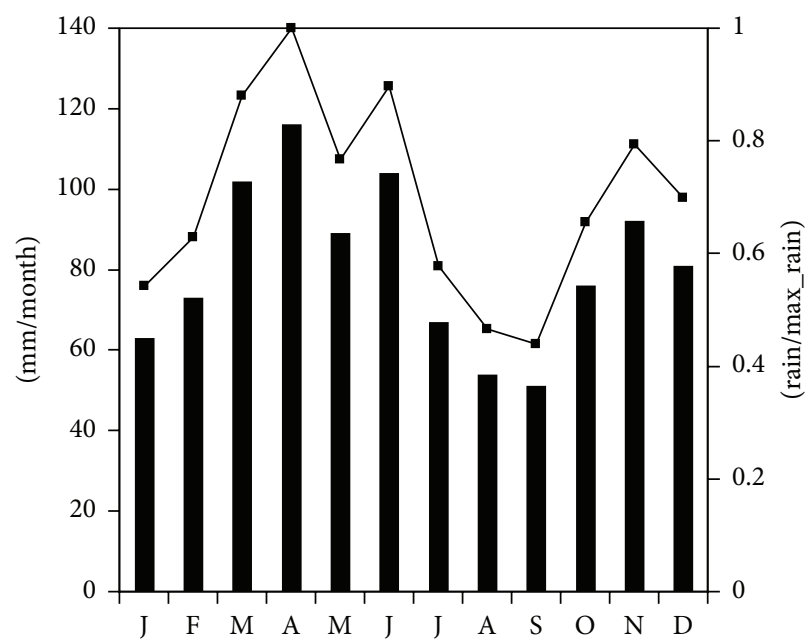

(c) $\mathrm{TM}$

FIGURE 3: The three seasonal precipitation regimens, average monthly rainfall (left $y$-axis) and normalized precipitation regimes (NPRs) (right $y$-axis). (a) Bimodal regime, (b) unimodal regime, and (c) three-modal regime.

the weights. Therefore the product of the scores multiplied by the weights represents the monthly influence of each PC, as a weighted score. In order to map the weighted scores to rainfall amounts, an exponential fitting is applied to monthly observed precipitation of 14 stations, generating pixel-wise monthly rainfall data. Because precipitation is a variable with positive values, the fitting to an exponential function was conducted.

Applied pixel-wise, the CFM rainfall model for each month is in general of the form

$$
P_{k}=\exp \left(c_{k}+\sum_{i=1}^{n} a_{i k} s_{i k} L_{i k}\right),
$$

where $P_{k}$ is the rainfall for the month $k$ th on a pixel, $a_{i k}$ and $c_{k}$ are regression coefficients for the $k$ th month, $s_{i k}$ is the score for the $k$ th month corresponding to the $i$ th principal component, and $L_{i k}$ is the weight for the $k$ th month corresponding to the $i$ th principal component.
For the validation of the model, the monthly precipitation was calculated for 5 stations not considered in the calibration group, and then the bias, the slope, and total variance explained by the model were calculated. Finally, area-wide seasonality of rainfall is derived from correlation analysis with NPRs.

3.1.4. Multiple Regression Model of Rainfall. A multiple linear regression model (MLRM) of rainfall is applied to generate area-wide data sets of NPRs. A principal component analysis (PCA) was applied to satellite-borne and GIS based data variables, and the 5 main principal components were used as inputs to the model. As in CFM, the main components were selected after the application of the scree test. The three satellite products are the aforementioned CF, LWP, and ZMIT, while the five GIS predictor variables encompass (i) the average potential radiation per month [33] as a proxy for the energy available for generation of local convection, (ii) the average monthly wind shelter as a proxy for the formation 
of advective rainfall [34], and (iii) latitude, longitude, and elevation as important predictors accounting for orographic effects.

Therefore, the multiple linear regression model of precipitation applied pixel-wise is

$$
P_{k}=c_{k}+\sum_{j=1}^{5} a_{k j} \mathrm{pcs}_{k j},
$$

where $P_{k}$ is the precipitation corresponding to the $k$ th month, $c_{k}$ is the regression coefficient independent term of the $k$ th month, $a_{k j}$ is the regression coefficient of the $j$ th principal component score (pcs), corresponding to the $k$ th month, and $\operatorname{pcs}_{k j}$ is the $j$ th pcs of $k$ th month. It is important to observe that, prior to PCA application, the variables derived from cloud products and GIS were normalized by subtracting the mean and then dividing by the standard deviation.

The MLRM was calibrated using the monthly precipitation for a group of 14 stations from UM, BM, and TM regimens. For the validation of the model, the monthly precipitation was calculated for 5 stations not considered in the calibration group, and then the bias, the slope, and total variance explained by the model were calculated. Then, area-wide seasonality of rainfall is derived from correlation analysis with NPRs.

3.2. Rainfall Dynamics and the Relation to Cloud Dynamics and Orography. In order to study the relation between rainfall dynamics with clouds dynamics and orography, we conducted (i) the synoptic analysis of dynamical variables and its relation to seasonal clouds products and (ii) the evaluation of NPRs along a representative transect in the Paute river basin. For (i), the analysis of the synoptic conditions was conducted using Hovmöller diagrams across a zonal transect from $270^{\circ}$ to $300^{\circ}$, averaged from latitude $-5^{\circ}$ to latitude $5^{\circ}$ versus the month of the year. The dynamical variables omega at $600 \mathrm{hPa}$ as a proxy for air vertical velocity influencing cloud formation, zonal and meridional winds at $600 \mathrm{hPa}$, influencing advection and orographic cloud and rain formation, and specific humidity at $600 \mathrm{hPa}$ are studied to explain the atmospheric processes throughout the year. To study the influence of synoptic conditions on the spatial distribution of CF, LWP, and ZMIT, the seasons MAM and JJA were studied. Concentrating on MAM is important because MAM is the rainiest season of the year for BM regions. On the other hand, JJA is the rainiest season for UM regions and the driest season for BM and TM regions. For (ii), we calculated the correlation between cloud products and NPRs across a representative transect in the Paute basin. East-west transect was considered because year-around easterlies are among the main climatic influences in the north-south oriented Andean mountains (profile location presented in Figure 1).

\section{Results and Discussion}

4.1. Delineation of Seasonal Regimes. Based on the evaluation of the maximum Kendall's tau correlation greater than 0.3 , comparing the three NPRs with CF, LWP, ZMIT, CFM, and MLRM, the representation of precipitation regimens delineation is presented in Figures 4(a)-4(e). Also, the pixels significant at 0.05 level were plotted in Figures $4(\mathrm{f})-4(\mathrm{j})$. As a reference for evaluating NPRs spatial delineation, the regionalization proposed by [7] was used, due to the lack of basin-wide rainfall observations availability. It was assumed that $\mathrm{UM}$ is $\mathrm{UM} 1$ and $\mathrm{UM} 2, \mathrm{BM}$ is BM1, and TM is BM2 in the present work and [7], respectively. The study areas on [7] present less area than the area used in the present study. However it is important to mention that delineation of rainfall seasonality furnished in [7] was based mostly on topographic features and a limited number of stations. It must be stressed that significance of correlation is given but only based on 12 values representing the monthly climatology. This means that correlation is very sensible to outliers and, thus, not a full spatial coverage of significant correlations can be expected. Also, it is important to highlight that although precipitation in complex terrain is highly variable in time and space, the spatial delineation of rainfall regimes using clouds products with $1 \mathrm{~km}$ resolution may be appropriate when considering the climate scale.

The result of the regionalization and pixels significant at 0.05 level using CF is presented in Figures 4(a) and 4(f). Correlation with UM NPR is not represented. Correlation with TM presents an irregular spotty pattern in the centre of the Paute basin. Correlation with BM, significant at 0.05 level, is shown in the centre of the Paute basin around BM stations Gualaceo and Jacarín, on the north, on the west nearby TM station El Labrado, and on the south next to TM station Cumbe. Although BM regime is depicted, however a clear delineation of seasonality is not represented. For LWP, regionalization and significant pixels at 0.05 level are presented in Figures 4(b) and 4(g). Isolated regions of BM towards the west near to BM station Sayausí, UM towards the north around UM stations Peñas Coloradas and Palmas, and TM to the southwest are presented. However a clear delineation of seasonality is not represented as well. Further, significant values at 0.05 level are present in just a few pixels. The regionalization of ZMIT (Figure 4(c)) represents the BM NPR in almost the full extent of the Paute basin. However significant values at 0.05 level (Figure 4(h)) are presented, in the centre to the west region. NPRs UM and TM are not represented by ZMIT. This fact points to a pronounced influence of convective clouds with greater top heights producing strong rainfall during MAM and SON. At the same time, regimes with enhanced rainfall during JJA are not represented by ZMIT. This fact might be due to the presence of low clouds.

For CFM the regionalization based on the maximum Kendall's tau correlation with NPRs and significant pixels at 0.05 level are presented in Figures 4(d) and 4(i). CFM was calibrated using the multiyear monthly mean precipitation of 14 stations and validated against 5 stations. The regression coefficients are presented in Table $4 . R^{2}$, bias, and slope are presented in Table 5. Although $R^{2}$ is low 0.357 in average, the spatial pattern of NPRs is similar to [7] regionalization, assuming that TM is BM2 in the cited work. CFM regionalization highlights the importance of orography in precipitation seasonality. UM regime in CFM is located in parallel to the orientation of the eastern cordillera, along the AOS. However, 


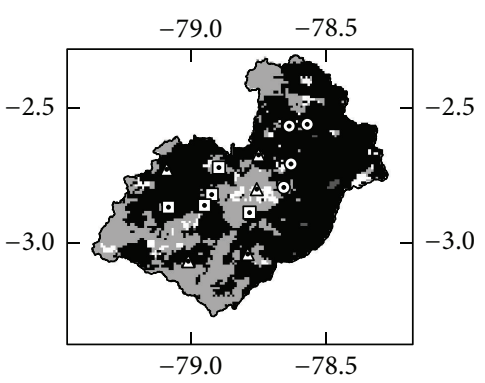

(a)

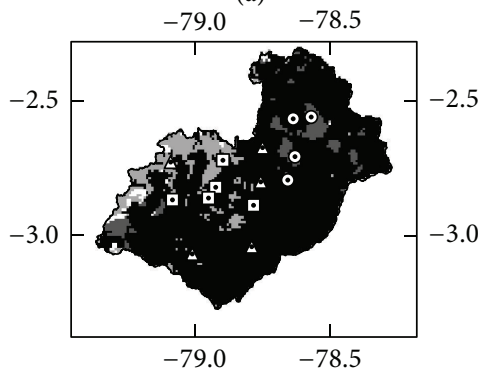

(b)

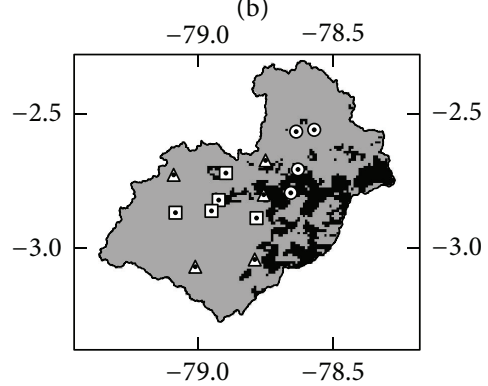

(c)

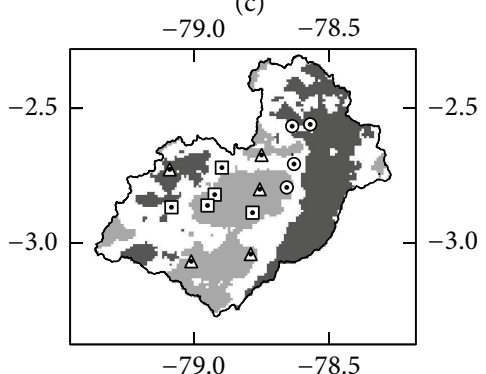

(d)

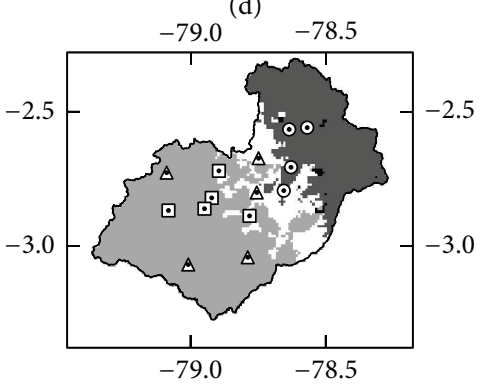

\begin{tabular}{ll} 
Rainfall regime & Rainfall stations \\
Kendall tau $<0.3$ & $\odot$ UM \\
UM & $\triangle$ TM \\
BM & $\bullet \mathrm{BM}$ \\
\hline TM &
\end{tabular}

(e)

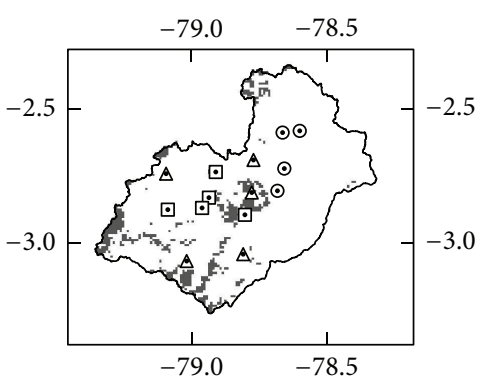

(f)
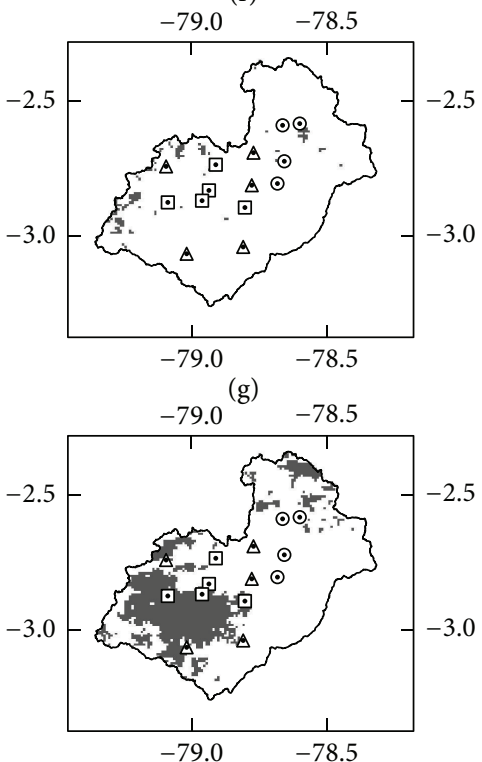

(h)

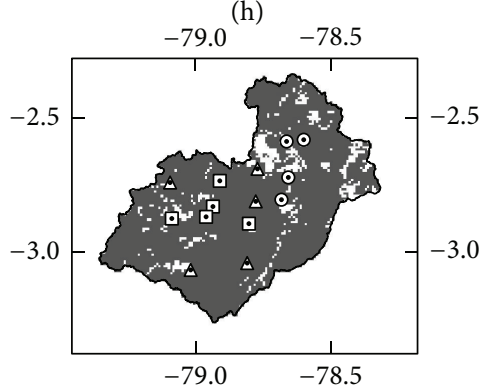

(i)

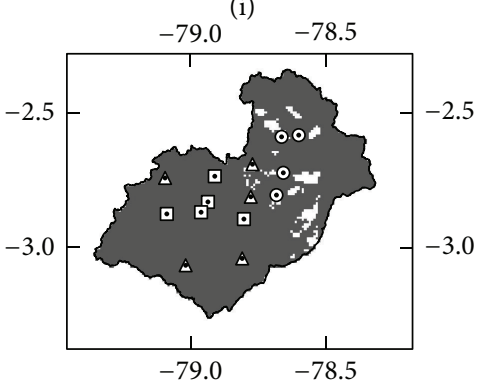

Significance Rainfall stations $\odot$ UM

$\triangle \mathrm{TM}$

$\bullet \mathrm{BM}$

(j)

FIGURE 4: Pixel-wise maximum Kendall tau correlation between NPRs UM, BM, and TM for CF (a), LWP (b), ZMIT (c), CFM (d), and MLRM (f). Only correlations greater than 0.3 are plotted. Corresponding significance of maximum correlation at 0.05 level for CF (f), LWP (g), ZMIT (h), CFM (i), and MLRM (j). 
TABLE 2: Multiple linear regression coefficients for the 5 main PCs.

\begin{tabular}{lcccccc}
\hline Month & $c$ & $a 1$ & $a 2$ & $a 3$ & $a 4$ & $a 5$ \\
\hline January & 63.10 & 3.24 & 5.80 & -7.45 & 3.20 & -5.69 \\
February & 75.84 & -0.84 & 4.27 & -5.69 & 3.31 & 7.17 \\
March & 103.78 & -2.28 & -9.78 & -0.78 & 4.45 & -10.15 \\
April & 127.35 & 1.25 & 10.96 & -8.24 & -4.52 & -0.47 \\
May & 95.23 & -8.50 & 12.70 & 15.82 & 0.97 & -4.52 \\
June & 102.10 & 5.47 & -17.48 & 22.95 & -27.38 & 21.41 \\
July & 66.13 & -21.30 & -5.13 & -3.02 & -14.41 & 1.83 \\
August & 53.04 & -7.39 & -5.71 & 17.49 & 15.44 & 10.53 \\
September & 52.82 & 6.05 & 3.67 & -1.71 & -10.09 & -11.60 \\
October & 80.50 & -0.12 & -0.41 & -10.16 & -1.65 & 0.77 \\
November & 99.25 & -1.53 & -11.52 & -4.87 & -6.41 & -9.29 \\
December & 88.62 & 0.90 & -1.01 & 5.70 & 11.68 & 15.59 \\
\hline
\end{tabular}

TABLE 3: Validation parameters for MLRM. Multiyear monthly mean precipitation observed versus modeled with MLRM. $R^{2}$, bias, and slope.

\begin{tabular}{lccc}
\hline Name & Bias & Slope & $R^{2}$ \\
\hline Esmeralda & -35.90 & 0.92 & 0.72 \\
Chanlud & -1.33 & 0.54 & 0.17 \\
Cuenca Aeropuerto & 5.51 & 0.92 & 0.85 \\
Portete & -34.81 & 0.59 & 0.54 \\
Jima & -61.33 & 0.79 & 0.22 \\
Average & $-25-57$ & 0.75 & 0.50 \\
\hline
\end{tabular}

in the region in front of the Paute canyon, UM regime enters the basin, highlighting the influence of this orographic feature for the climate of the basin. The region with the UM regime is important for the Paute hydroelectric power production and, thus, of major importance for the Ecuadorian economy. Therefore it is an important feature that must be properly captured by any rainfall delineation scheme.

A drawback of CFM is the overrepresentation of UM regime on a short extension in the western part of the basin, but it is important to acknowledge that the model captures the enhancement of rainfall on the eastern flanks of the eastern and the western cordillera. This enhancement of rainfall might be due to the orographic lifting of air on the windward side of the cordillera, forcing convection and rainfall. For CFM, TM is mainly present across the Paute basin, and BM regime is located only in regions sheltered by the eastern cordillera. Also, the TM regime divides the basin due to the influence of the passage of clouds between Mounts Bellavista and El Calvario (Figure 1). This feature is absent in [7] but still necessary to be confirmed. The CFM model points out that TM is a transition state between UM and BM regimens. Therefore on the unsheltered eastern flanks of the cordillera UM and TM NPRs are expected, and BM NPR is more present in isolated sheltered regions.

The regionalization based on maximum Kendall's correlation greater than 0.3 and significance at 0.05 level of MLRM with NPRs are presented in Figures 4(e) and 4(j). As CFM,
TABLE 4: CFM regression coefficients for the 3 main PCs.

\begin{tabular}{lcccc}
\hline Month & $c$ & $a 1$ & $a 2$ & $a 3$ \\
\hline January & 3.90 & -0.55 & 0.01 & 0.12 \\
February & 4.18 & 0.27 & -0.01 & 0.04 \\
March & 4.58 & -0.12 & 0.00 & -0.04 \\
April & 4.76 & -0.28 & -0.02 & -0.07 \\
May & 4.83 & 0.14 & -0.01 & 0.05 \\
June & 4.82 & 0.15 & 0.04 & -0.29 \\
July & 4.59 & 0.09 & -0.42 & 1.21 \\
August & 4.06 & 0.09 & -0.05 & 0.93 \\
September & 4.20 & 0.10 & -0.03 & -0.03 \\
October & 4.35 & -0.65 & -0.02 & 0.16 \\
November & 4.60 & 0.10 & -0.03 & 0.04 \\
December & 4.21 & 0.10 & -0.23 & 0.33 \\
\hline
\end{tabular}

TABLE 5: Validation parameters for CFM. Multiyear monthly mean precipitation observed versus modeled with CFM. $R^{2}$, bias and slope.

\begin{tabular}{lccc}
\hline Name & Bias & Slope & $R^{2}$ \\
\hline Esmeralda & 31.34 & 0.63 & 0.21 \\
Chanlud & -68.24 & 1.21 & 0.49 \\
Cuenca Aeropuerto & 26.80 & 0.58 & 0.61 \\
Portete & 18.52 & 0.26 & 0.32 \\
Jima & 32.99 & 0.34 & 0.16 \\
Average & 8.28 & 0.60 & 0.36 \\
\hline
\end{tabular}

the MLRM was calibrated using multiyear monthly mean precipitation of 14 stations and validated with 5 stations. The regression coefficients are presented in Table 2. $R^{2}$, bias, and slope between the model results and the observations of 5 stations are presented in Table 3. The delineation of MLRM presents the BM regime located toward the west and southwest of the basin. UM is depicted on the north and northeast. TM regime is located between BM and UM regions, rightly represented as a mix between these two regimes. However, there is a lack of representation of TM on the eastern flank of the western cordillera on higher elevation slopes, missing therefore the enhancement of precipitation during JJA due to orographic features. It is interesting to observe that MLRM captures UM region on the Paute canyon area. This fact might be due to the consideration of orographic variables. A drawback of the model is the overestimation of UM influences in the northern part of the basin, where $\mathrm{BM}$ regime was found by [7]. In comparison with CFM regionalization, where UM is located in parallel to the eastern flanks of the eastern cordillera, MLRM lack UM representation along these regions.

To summarize the previous results, in Table 6 the pixelwise evaluation of seasonality of CF, LWP, ZMIT, MLRM, and CFM was conducted against regionalization proposed by authors of [7], presupposing that TM is BM2 on their study. It is important also to highlight that the region considered in [7] study covers less area than the region considered in 
TABLE 6: Concordance of seasonal regimens of cloud frequency, liquid water path, average cloud top height, multiple linear regression model of rainfall, and PCA cloud frequency model of rainfall against Célleri’s regionalization.

\begin{tabular}{lc}
\hline Approach & Concordance (\%) \\
\hline CF & 17.05 \\
LWP & 19.52 \\
ZMIT & 16.71 \\
MLRM & 46.88 \\
CFM & 53.67 \\
\hline
\end{tabular}

the present study. The station-wise evaluation of seasonality representation by the models was also possible, but this approach does not give information about the extended spatial delineation representation. Therefore, in order to make a distributed evaluation score, pixels with a perfect match were assigned a value of 1 and 0 otherwise. In order to calculate the total concordance the summation of all pixels is calculated and then divided by the number of pixels. The results show that MRLM and CFM outperformed CF, LWP, and ZMIT, with CFM presenting a slightly higher concordance score.

The spatial representation of the seasonality of rainfall in the Paute basin was better conveyed by the MLRM and CFM models of rainfall. Quantitatively, regarding the pixel-wise evaluation of seasonality representation (Table 6), the two models present similar coincidences, CFM with slightly higher values, although it is important to stress that the evaluation was developed against [7] based mostly on topographical features, besides the fact that the region considered for evaluation does not cover the eastern slopes of the Paute basin toward the Amazon, where strong differences in seasonality representation between the two models arise. Furthermore, the validation of the two rainfall models was conducted against the monthly rainfall of 5 stations, displaying on average similar results. Qualitatively, MLRM is able to represent $\mathrm{UM}, \mathrm{BM}$, and partly TM regions in the transition zone from the lower to the upper part of the Paute basin. However, the lack of representation of TM regions on the western slopes of the Paute basin oriented to the east is an important drawback of the MLRM model.

With regard to CFM, it is able to represent $\mathrm{UM}, \mathrm{BM}$, and the transitional TM region: the seasonal delineation resembles the one presented in [7] (considering TM as equivalent to BM2). A remarkable capability of this model is the good representation of the BM regime in the sheltered regions to the easterlies. Another important feature is the representation of the shift of seasonality from UM to TM on the northernmost part of the basin towards higher elevations. A drawback of this model is the overrepresentation of UM on a small area in the western slopes of the western cordillera eastward oriented. As a general finding, the NPRs delineation highlighted the relation between the precipitation regime and the orographic features in the $\mathrm{PB}$. Thus, in order to understand the spatiotemporal dynamics of precipitation and clouds, as well as the potential cross-scale generation processes of rainfall in the $\mathrm{PB}$, further analysis is conducted.

\subsection{Spatiotemporal Analysis of Cloudiness and Consequences for Rainfall Seasonality Related to Orography}

4.2.1. Analysis of Synoptic Conditions and Seasonal Cloud Products. To understand the atmospheric conditions producing rainfall and clouds in the Paute river basin, the longterm 1981-2010 multiyear monthly mean omega, zonal wind, meridional wind, and specific humidity were studied. We used Hovmöller diagrams across a zonal transect from $270^{\circ}$ to $300^{\circ}$ averaged from latitude $-5^{\circ}$ to latitude $5^{\circ}$ versus the month of the year (Figure 5). Omega negative values (up oriented) mean ascending air, enhanced convection, the development of clouds, and therefore more probability of rainfall. On the other hand, positive values of omega (down oriented) imply subsidence, producing inhibition of clouds formation and rainfall. From Figure 5(a), a relative peak of omega is evident, from February to April. Therefore higher cloud formation and rainfall of convective nature are expected during this season. This is related to the rainy season MAM. On the other hand, from June to September, omega positive values mean subsidence, inhibiting cloud formation and rainfall, accounting for the drier season for BM regions. Also, due to subsidence lower clouds are expected. From October, omega values are low negative again until December, where higher negative values are presented. Although subsidence during JJA accounts for the drier season in BM regions, however, JJA is the rainiest season for UM regions, and TM regions present a shallow peak in rainfall in June. To account for JJA precipitation in UM and TM regions, the analysis of horizontal winds and specific humidity is important. Figure 5(b) shows that easterly winds influence the Paute basin throughout the year, with values markedly stronger during JJA. Further, in Figure 5(c), the highest values of specific humidity are present from April to July. This fact points to strong easterlies with high content of moist, which are cooled adiabatically due to the raising air along the eastern slopes of the cordillera, enhancing clouds and precipitation along the escarpments of the cordillera. Similar situation might occur, to a lesser extent, on the eastern slopes of the western cordillera, accounting for a shallow peak in clouds and rainfall in June. We, also, studied meridional winds; however results are not presented, because, intraannual variation was not significant.

Therefore, in order to explain the rainfall dynamics of the seasonal regimens in the study area, the driving macroand mesoscale mechanisms should be considered. Rainfall seasonality near the equator around the world is mainly BM with local variations [35-37]. This seasonal regime is characterized by two rainy seasons, that is, one during MarchApril and the second one during October-November with a dry season during June-July. The rainfall behavior is related to the evolution of the ITCZ, and, thus, the rainfall mainly develops due to convective processes. To support this fact, we used omega as a proxy for vertical velocity which influences convection (Figure 5(a)). This fact is also confirmed by the study of outgoing longwave radiation in tropical regions by [38]. Rainfall seasonality toward the east of the Paute basin on the Amazon basin is reported to be BM near equatorial areas [39]. On the contrary, toward the west in the coastal plains 


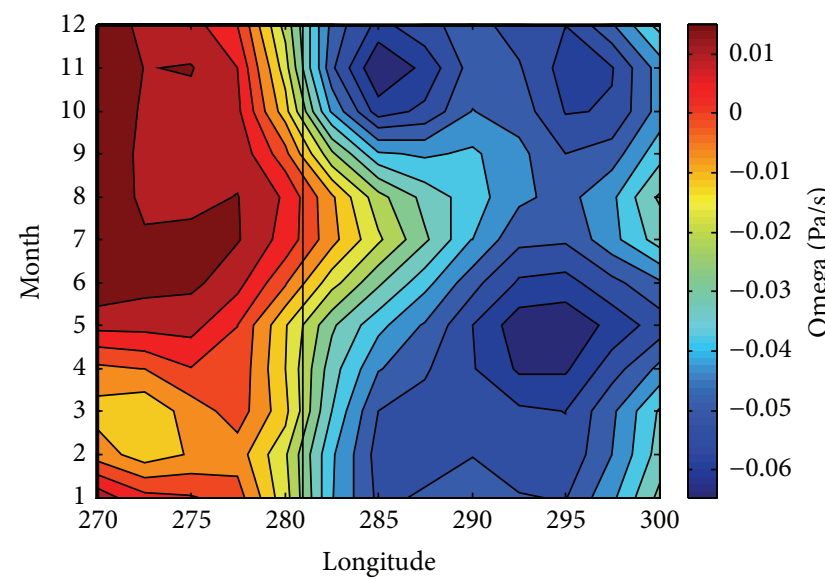

(a)

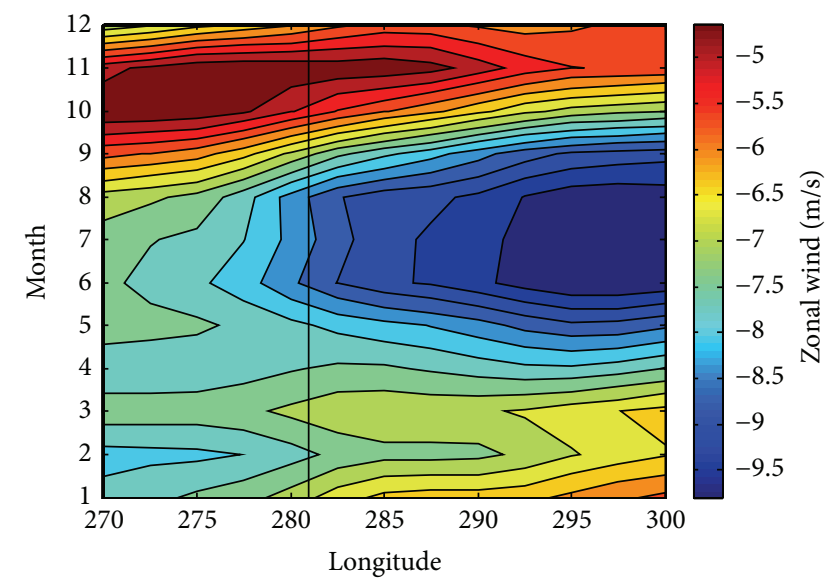

(b)

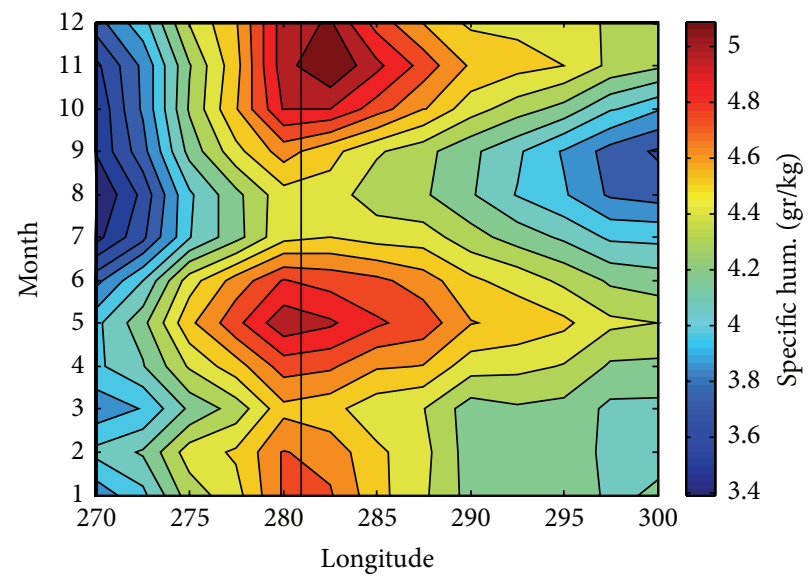

(c)

Figure 5: Hovmöller diagram across a longitudinal transect from $270 \mathrm{E}$ to $300 \mathrm{E}$ averaged from $5 \mathrm{~S}$ to $5 \mathrm{~N}$ of (a) omega $600 \mathrm{hPa}$, (b) zonal velocity wind $600 \mathrm{hPa}$, and (c) specific humidity $600 \mathrm{hPa}$ versus the months of the year. The black line located at 281E represents the Paute basin.

of Ecuador, the precipitation regime observed describes one rainy season from December to April with its maximum in March. The second rainy season during October is suppressed [4]. Therefore considering the UM regime with its maximum in June-July, available on the eastern part of the Paute river basin, rainfalls are expected to develop due to local effects. On the other side, subsidence in JJA is due to intensified Walker circulation, producing advective low clouds rather than the formation of deep convective activity. Thus, the June-July precipitation maximum for UM and TM regions is strongly linked to the synoptic scale state of the Walker circulation. UM or TM with the June-July maximum should be related to unsheltered windward sides of the slopes where local to mesoscale forced convection counteracts macroscale subsidence induced by the seasonality of the Walker circulation, as explained before. Because of the northward shift of the ITCZ during this season, stronger easterlies are enabled to enhance the advection of moisture toward the eastern slopes of the Andes (Figures 5(b) and 5(c)). These findings are supported by the study of [40]. They found that the east-west water vapor flux is highest for May-June $\left(215 \mathrm{~kg} \mathrm{~m}^{-1} \mathrm{~s}^{-1}\right)$ at $2.5^{\circ} \mathrm{S}$,
$77.5 \mathrm{~W})$ with a zonal orientation, increasing the precipitation on the windward side of the cordillera.

To study the influence of the atmospheric synoptic conditions on cloud products, the average CF, LWP, and ZMIT for MAM and JJA are presented in Figure 6 for the Paute catchment. CF for MAM and JJA is presented in Figures 6(a) and 6(b), respectively. During MAM, CF is high across the Paute basin pointing out a generalized convective situation, affecting UM, BM, and TM stations. During MAM, the wetter season for BM and TM regimes, convective cloud formation is common due to ITCZ passages. Toward the coastal plains increased values of $\mathrm{CF}$ coincide with the rainiest season during MAM. For JJA, CF is much lower with respect to MAM, with the exception of the regions along the eastern slopes. This fact reveals (i) that across the basin the dry season is present during JJA and more evidently marked on the sheltered inter-Andean valleys and (ii) that there is a band-like pattern of enhanced CF and rainfall along AOS, where UM regime could be dominant. Therefore clouds and rainfall are strongly dependent on the easterlies exposure in the Paute basin. As a confirmation to this fact, on the 


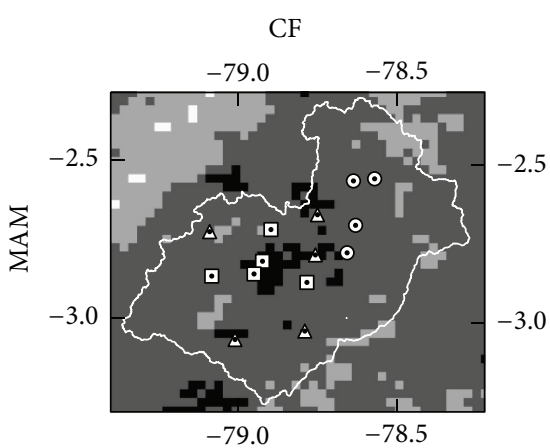

(a)
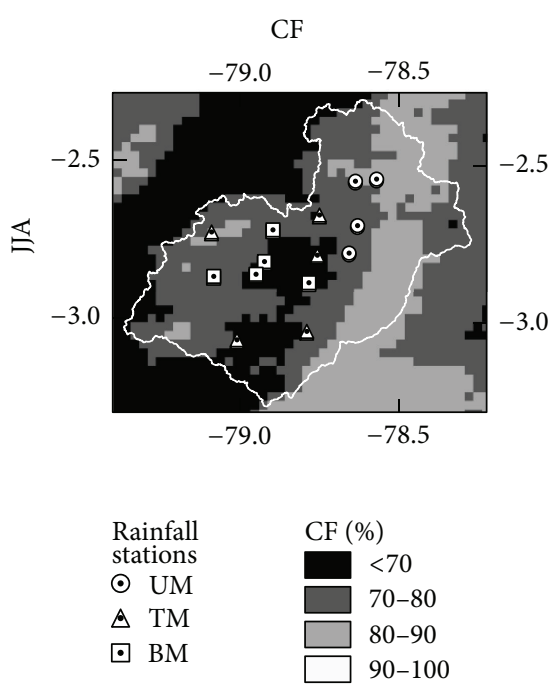

(b)

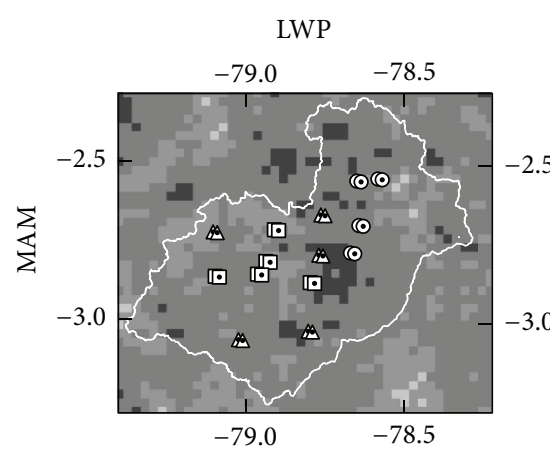

(c)

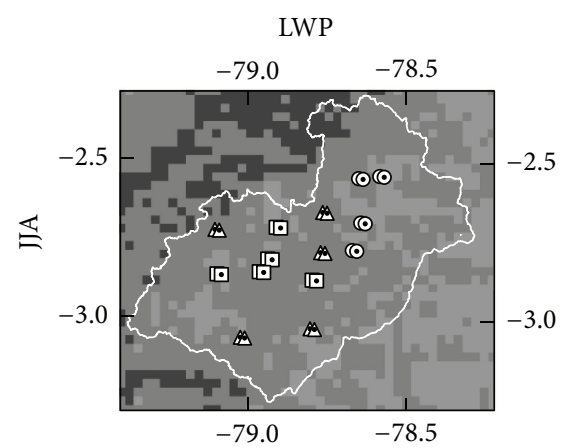

\begin{abstract}
Rainfall
$\odot$ UM

$\triangle \mathrm{TM}$

$\bullet \mathrm{BM}$
\end{abstract}

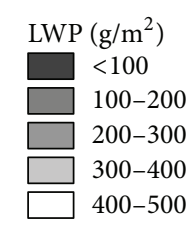

(d)

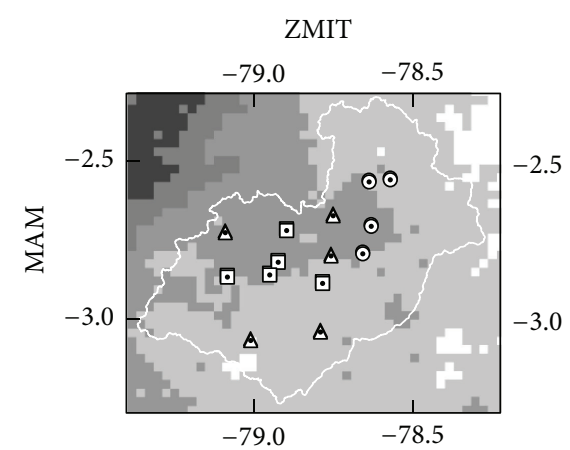

(e)

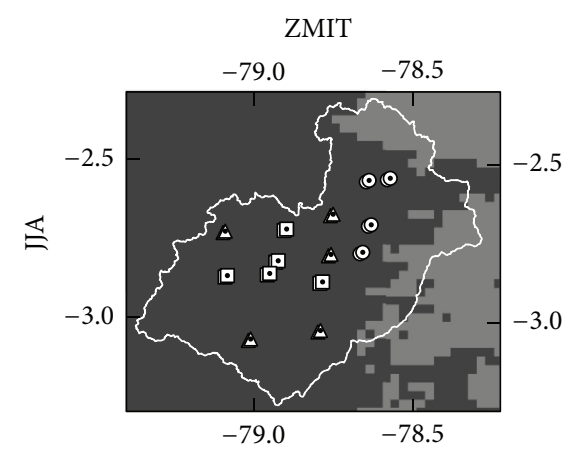

$\begin{array}{ll}\begin{array}{l}\text { Rainfall } \\ \text { stations }\end{array} & \text { ZMIT (m a.s.l.) } \\ \odot \text { UM } & <5000 \\ \odot \text { TM } & 5000-5500 \\ \odot \text { BM } & 5500-6000 \\ & \square 6000-6500 \\ & \square 6500-7000\end{array}$

(f)

FIGURE 6: Seasonal average for CF, LWP, and ZMIT (left, centre, and right columns) during MAM and JJA seasons (top and bottom rows).

western escarpment of the western cordillera toward the coastal plains, a lee effect is evident during JJA for CF and LWP (Figures 6(b) and 6(d)). The resemblance between CF patterns during JJA with CFM seasonality delineation (Figure 6) is striking, pointing to the importance of the Amazon influence on seasonality of precipitation and climate for the basin.

For liquid water path, a more patchy structure can be observed during MAM due to convective cloud formation. In JJA LWP is depicted as an east-to-west decreasing gradient (Figures 6(c) and 6(d)). This points to advective clouds with high content of water originating from the Amazon influencing the Paute basin. During JJA UM stations are affected as well as TM stations located at the eastern escarpment of the western cordillera. The strong decrease in LWP and CF toward the west of the basin in the western flanks of the western cordillera confirms the findings of [4] that the Andes act as a weather divide. For ZMIT, values during MAM are higher due to the generally more convective predisposition compared to JJA. On average, ZMIT in JJA is around $80 \%$ the value of annual mean of ZMIT for the stations selected in the present study. This is due to the general tendency for a subsiding air in the Walker circulation during this season.
Thus, inhibition of convective cloud formation accounts for lower ZMIT values of the prevailing lower advective clouds.

4.2.2. The Influence of Orography on Cloud Products. Regarding the relation between orography, cloud frequency, and rainfall, in Figure 7 a west-east cross section through the Paute basin generally depicts five different zones: (i) The eastern foothills show a tendency that $\mathrm{CF}$ is more related to BM and TM NPR. (ii) This changes at escarpment heights around $2300 \mathrm{~m}$ a.s.l. where high cloudiness in BM and TM means low precipitation. The weak positive correlations between CF and UM point out that UM rainfall is concomitant with a peak in CF possibly related to AOS region running parallel to the Andes. (iii) At the windward side of the western crest altitude (at approx. $3000 \mathrm{~m}$ a.s.l.), TM and BM NPRs positively correlate very similarly with CF which means that this is the most distinct area where different cloud processes leading to BM and UM NPR are blended. (iv) The basin between the eastern and the western crest altitudes is most dominated by BM related cloud processes; UM is clearly negatively correlated to CF which means rain minima in JJA are a result of minima in CF. (v) The western slopes of the 


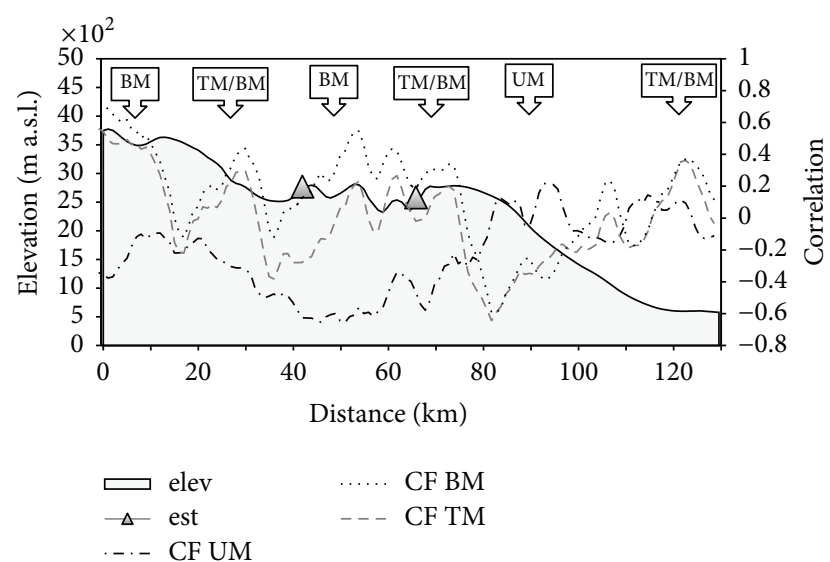

FIgURe 7: Profile of elevation and Pearson correlation of CF with $\mathrm{UM}, \mathrm{BM}$, and TM normalized observational precipitation regimens. (For the location of the profile line refer to Figure 1.)

eastern crest at $3000 \mathrm{~m}$ a.s.l. clearly resemble the situation of the blended UM/BM TM regime of (iii).

\section{Summary}

In the Paute river basin three defined precipitation regimes can be differentiated: UM, BM, and TM. AOS might produce the UM regime in the Paute basin due to the air masses coming from the Amazon through the Paute Canyon, diminishing its influence toward higher elevations, shifting the seasonality of rainfall to TM regime. Therefore, the AOS influence on the eastern slopes of the cordillera is important, and a clear BM seasonality is possible just in the intervalley locations most sheltered against the influence of the easterlies. An indirect influence from the Amazon is evident for TM stations on the eastern oriented slopes of the western cordillera as El Labrado and Chanin, and, to a lesser extent, for Biblian (Figure 1). Also a direct but weaker influence is detectable for the stations Sigsig and Cumbe due to the passage of clouds between Mounts Bellavista and El Calvario, although there is a high interannual variability of the June-July peak (Figure 1).

Similar climatological conditions, as those occurring in the Paute basin, are expected along the Andes cordillera in tropical latitudes. For instance, in [4] UM regime was found to be located in elevations greater than $1000 \mathrm{~m}$ a.s.l. on the eastern slopes along the eastern cordillera, as stations Papallacta (3160 m a.s.l.), Baños (1843 m a.s.l.), and Sucua (910 $\mathrm{m}$ a.s.l.). Confirming these results UM stations in the present study were found above $1000 \mathrm{~m}$ a.s.l. in stations Palmas (2400 m), Sevilla de Oro (2360 m), Peñas Coloradas $(2321 \mathrm{~m})$, and Mazar $(2450 \mathrm{~m})$. This fact confirms that UM regime along the eastern slopes of the cordillera might be due to the influence of AOS, and, further, it is evident that the presence of UM regime in the lower part of the Paute basin might be more related to the local influence of AOS [30]. With respect to the transitional regime between UM and BM, TM in [4] was found toward the east in lower elevations such as Puyo (960 m a.s.l.), Sangay ( $880 \mathrm{~m}$ a.s.l.), and Tena (665 $\mathrm{m}$ a.s.l.) concluding that TM regime is confined

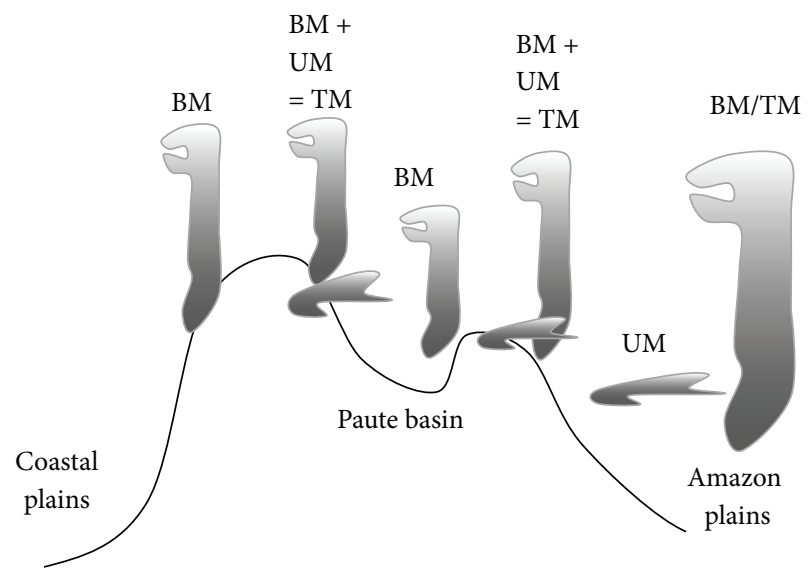

FIGURE 8: Conceptual model of seasonal rain formation for the Rio Paute catchment area.

between 700 and $1000 \mathrm{~m}$ a.s.l. in basins with outlet toward the eastern cordillera. However, in the present study TM was found toward the west in higher elevations, as El Labrado (3335 $\mathrm{m}$ a.s.l.) and Chanin ( $3270 \mathrm{~m}$ a.s.l.). In consequence, it seems plausible that the TM regime is present above and below the rain and clouds band produced by the AOS. Further studies are necessary on the processes and influence for cloud formation and rainfall on AOS along the eastern slopes of the eastern cordillera in Ecuador, even more importantly knowing that rainfall along this region could influence strategic hydroelectrical projects for the Ecuadorian economy.

Based on these findings, Figure 8 describes a conceptual model of rainfall seasonality in inter-Andean basins like the Paute basin. The basin gets rainfall all over the year mainly from high convective clouds. On the eastern slopes of the eastern cordillera, a zone of advective cloud immersion exists particularly in JJA where especially moist but shallow cap clouds lead to the UM rainfall maximum. JJA rainfall at windward slopes seems therefore to be due to an advective barrage effect. The BM rainfall is of typical convective character during the equinoxes. The increase of the TM rainfall regime shows that the clear convective BM regime is blended with cloud advection where the latter also leads to some additional rainfall in JJA, mostly not exceeding the more convective rains in the BM seasons.

The high spatiotemporal variability in the Paute river basin, which is summarized as the conceptual model presented in Figure 8, shows that although the ITCZ plays an important role in enhancing convection throughout the year, the strengthening of the Walker circulation producing subsidence, during boreal summer, accounts for the dry season of the inter-Andean regions. Also, of major importance is the influence during boreal summer of the easterlies bringing moist air from the Amazon, which enhances the precipitation amounts on the eastward oriented slopes. The enhancement of precipitation is due to low advective shallow cap clouds along AOS. The interannual precipitation variability due to climatic influences as ENSO is weak in the Paute basin [10], due to the fact that the western cordillera, higher than the eastern cordillera around this latitude, limits the influence 
of the Pacific Ocean sea surface temperature, as is the case for the coastal plains of the country. These facts highlight the importance of considering the interplay between the climatic factors and the orography for determining rainfall variability in regions of complex topography.

\section{Conclusions}

The main aim of the present study was to understand the spatiotemporal dynamics of precipitation and clouds, and the potential cross-scale generation processes of rainfall in the Paute basin, located in the Andes of Ecuador. Precipitation models using satellite cloud products and GIS data reveal the spatial extension of three regimes: A three-modal (TM) regime mainly present across the basin, a bimodal (BM) regime, typical for sheltered valleys, and a unimodal (UM) regime at windward slopes of the eastern cordillera. The spatiotemporal analysis shows that the ITCZ plays an important role in enhancing convection throughout the year. However, during boreal summer, the strengthening of the Walker circulation produce subsidence, accounting for the dry season of the inter-Andean regions. Of major importance is the influence during boreal summer of the easterlies bringing moist air from the Amazon, which enhances the precipitation amount on the eastward oriented slopes. Therefore, low advective shallow cap clouds mainly cause precipitation in unimodal regions. Due to these facts, the three-modal seasonality is the main regime for this region in the Andes, where the western cordillera is higher than the eastern cordillera, while bimodal regime only occurred on sheltered valleys with precipitation mainly of convective nature. Further, in altitudes from 1000 to $3000 \mathrm{~m}$ a.s.l. on the eastern flanks of the eastern cordillera, unimodal regimes feature a maximum in June-July. The precipitation is mainly of advective nature related to the rainfall and clouds band, Andean Occurring System. Therefore, three-modal regime is suggested to be a mixture between UM and BM, characterized by both convective and advective influences.

The use of remote sensing showed to be a feasible tool to study climatology for case studies in highly complex terrain. Moreover, this work adds to a thin literature on convective and advective variability in the tropical Andes. Although models cannot be a substitute for observations, the use of regional climate models is also necessary to understand the underlying mechanisms occurring on such a complex terrain. However, it demands an exhaustive sensitivity analysis of the parameterizations in order to be able to represent the precipitation and cloud dynamics on this region. Further investigations will be oriented on this direction in future studies.

\section{Acronyms}

UM: Unimodal regime of rainfall

BM: Bimodal regime of rainfall

TM: Three-modal regime of rainfall

NPR: Normalized precipitation regime

CFM: Cloud frequency based model of rainfall

MLRM: Multiple linear regression model

CF: $\quad$ Cloud frequency
LWP: Cloud liquid water path

ZMIT: Cloud top height

ENSO: El Nino Southern Oscillation

ITCZ: Intertropical convergence zone

AOS: Andean Occurring System

MAM: March-April-May

JJA: June-July-August.

\section{Conflict of Interests}

The authors declare that there is no conflict of interests regarding the publication of this paper.

\section{Acknowledgments}

Lenin Campozano was funded by a grant provided by SENESCYT (Secretaría Nacional de Educación Superior, Tecnología e Innovación). Complementary funding was provided by MICMOR (Helmholtz Research School on Mechanisms and Interactions of Climate Change in Mountain Regions). The authors acknowledge the institutions that provided data: INAMHI (Instituto Nacional de Meteorología e Hidrología) and ETAPA (Empresa Municipal de Telecomunicaciones, Agua Potable y Saneamiento). Thanks are due to IERSE (Instituto de Estudios de Régimen Seccional del Ecuador) for information of the Paute basin. Special thanks are due to Dr. Patrick Laux for helpful comments on the paper. German Research Foundation (DFG) (PAK825: BE1780/38-1, TR1201/1-1) is also acknowledged.

\section{References}

[1] D. Viviroli, H. H. Dürr, B. Messerli, M. Meybeck, and R. Weingartner, "Mountains of the world, water towers for humanity: typology, mapping, and global significance," Water Resources Research, vol. 43, no. 7, 2007.

[2] P. Pourrut and G. Gómez, "El Ecuador al cruce de varias influencias climáticas. Una situación estratégica para el estudio del fenómeno El Niño," Bulletin de l'Institut Français d'Études Andines, vol. 27, no. 3, pp. 449-457, 1998.

[3] M. Coltorti and C. D. Ollier, "Geomorphic and tectonic evolution of the Ecuadorian Andes," Geomorphology, vol. 32, no. 1-2, pp. 1-19, 2000.

[4] J. Bendix and W. Lauer, "Die niederschlagsjahreszeiten in Ecuador und ihreklimadynamische interpretation," Erdkunde, vol. 46, pp. 118-134, 1992.

[5] R. Rollenbeck and J. Bendix, "Rainfall distribution in the Andes of southern Ecuador derived from blending weather radar data and meteorological field observations," Atmospheric Research, vol. 99, no. 2, pp. 277-289, 2011.

[6] R. Mejia, G. Ontaneda, D. Molinaro, and F. Rossel, Homogenizacion y Regionalizacion de la Pluviometria en la Cuenca del Rio Paute, Serie INSEQ, Repuública del Ecuador, Ministerio de Energía y Minas, INAMHI, ORSTOM, Quito, Ecuador, 1996.

[7] R. Célleri, P. Willems, W. Buytaert, and J. Feyen, "Spacetime rainfall variability in the Paute basin, Ecuadorian Andes," Hydrological Processes, vol. 21, no. 24, pp. 3316-3327, 2007.

[8] W. Buytaert, R. Celleri, P. Willems, B. D. Bièvre, and G. Wyseure, "Spatial and temporal rainfall variability in mountainous areas: 
a case study from the south Ecuadorian Andes," Journal of Hydrology, vol. 329, no. 3-4, pp. 413-421, 2006.

[9] J. Bendix, K. Trachte, E. Palacios et al., "El Niño meets La Niña anomalous rainfall patterns in the traditional El Niño region of Southern Ecuador," Erdkunde, vol. 65, no. 2, pp. 151-167, 2011.

[10] D. E. Mora and P. Willems, "Decadal oscillations in rainfall and air temperature in the Paute River Basin-Southern Andes of Ecuador," Theoretical and Applied Climatology, vol. 108, no. 1-2, pp. 267-282, 2012.

[11] J. Bendix, R. Rollenbeck, D. Göttlicher, and J. Cermak, "Cloud occurrence and cloud properties in Ecuador," Climate Research, vol. 30, no. 2, pp. 133-147, 2006.

[12] A. Ochoa, L. Pineda, P. Willems, and P. Crespo, "Evaluation of TRMM 3B42 (TMPA) precipitation estimates and WRF retrospective precipitation simulation over the Pacific-Andean basin into Ecuador and Peru," Hydrology and Earth System Sciences Discussions, vol. 11, no. 1, pp. 411-449, 2014.

[13] A. Ochoa, L. Campozano, E. Sánchez, R. Gualán, and E. Samaniego, "Evaluation of downscaled estimates of monthly temperature and precipitation for a southern Ecuador case study," International Journal of Climatology, 2015.

[14] D. E. Mora, L. Campozano, F. Cisneros, G. Wyseure, and P. Willems, "Climate changes of hydrometeorological and hydrological extremes in the Paute basin, Ecuadorean Andes," Hydrology and Earth System Sciences, vol. 18, no. 2, pp. 631-648, 2014.

[15] W. Buytaert, R. Célleri, and L. Timbe, "Predicting climate change impacts on water resources in the tropical Andes: effects of GCM uncertainty," Geophysical Research Letters, vol. 36, no. 7, Article ID L07406, 2009.

[16] W. Buytaert, M. Vuille, A. Dewulf, R. Urrutia, A. Karmalkar, and R. Célleri, "Uncertainties in climate change projections and regional downscaling in the tropical Andes: implications for water resources management," Hydrology and Earth System Sciences, vol. 14, no. 7, pp. 1247-1258, 2010.

[17] J. Bendix, K. Trachte, J. Cermak, R. Rollenbeck, and T. Nauß, "Formation of convective clouds at the foothills of the tropical eastern Andes (South Ecuador)," Journal of Applied Meteorology and Climatology, vol. 48, no. 8, pp. 1682-1695, 2009.

[18] K. Trachte and J. Bendix, "Katabatic flows and their relation to the formation of convective clouds-idealized case studies," Journal of Applied Meteorology and Climatology, vol. 51, no. 8, pp. 1531-1546, 2012.

[19] W. Buytaert and B. de Bievre, "Water for cities: the impact of climate change and demographic growth in the tropical Andes," Water Resources Research, vol. 48, no. 8, Article ID W08503, 2012.

[20] B. De Bièvre, A. Alvarado, L. Timbe, R. Célleri, and J. Feyen, "Night irrigation reduction for water saving in medium-sized systems," Journal of Irrigation and Drainage Engineering, vol. 129, no. 2, pp. 108-116, 2003.

[21] G. M. Mosquera, P. X. Lazo, R. Célleri, B. P. Wilcox, and P. Crespo, "Runoff from tropical alpine grasslands increases with areal extent of wetlands," Catena, vol. 125, pp. 120-128, 2015.

[22] W. Buytaert, J. Deckers, and G. Wyseure, "Description and classification of nonallophanic Andosols in south Ecuadorian alpine grasslands (páramo)," Geomorphology, vol. 73, no. 3-4, pp. 207221, 2006.

[23] R. Padrón, B. Wilcox, P. Crespo, and R. Célleri, "Rainfall in the Andean Páramo: new insights from high-resolution monitoring in Southern Ecuador," Journal of Hydrometeorology, vol. 16, no. 3, pp. 985-996, 2015.
[24] M. Córdova, G. Carrillo-Rojas, P. Crespo, B. Wilcox, and R. Célleri, "Evaluation of the Penman-Monteith (FAO 56 PM) method for calculating reference evapotranspiration using limited data: application to the Wet Páramo of Southern Ecuador, Mountain Research and Development, vol. 35, no. 3, pp. 230-239, 2015.

[25] W. Buytaert, F. Cuesta-Camacho, and C. Tobón, "Potential impacts of climate change on the environmental services of humid tropical alpine regions," Global Ecology and Biogeography, vol. 20, no. 1, pp. 19-33, 2011.

[26] X. L. Wang, "Accounting for autocorrelation in detecting mean shifts in climate data series using the penalized maximal $\mathrm{t}$ or $\mathrm{F}$ test," Journal of Applied Meteorology and Climatology, vol. 47, no. 9, pp. 2423-2444, 2008.

[27] X. L. Wang, "Penalized maximal F test for detecting undocumented mean shift without trend change," Journal of Atmospheric and Oceanic Technology, vol. 25, no. 3, pp. 368-384, 2008.

[28] L. Campozano, E. Sánchez, A. Aviles, and E. Samaniego, "Evaluation of infilling methods for time series of daily precipitation and temperature: the case of the Ecuadorian Andes," Maskana, vol. 5, no. 1, pp. 99-115, 2014.

[29] J. Bendix, R. Rollenbeck, and W. E. Palacios, "Cloud detection in the tropics a suitable tool for climate-ecological studies in the high mountains of Ecuador," International Journal of Remote Sensing, vol. 25, no. 21, pp. 4521-4540, 2004.

[30] A. Bendix and J. Bendix, "Heavy rainfall episodes in Ecuador during El Niño events and associated regional atmospheric circulation and SST patterns," Advances in Geosciences, vol. 6, pp. 43-49, 2006.

[31] E. Kalnay, M. Kanamitsu, R. Kistler et al., "The NCEP/NCAR 40-year reanalysis project," Bulletin of the American Meteorological Society, vol. 77, no. 3, pp. 437-471, 1996.

[32] B. Thies, T. Nauss, and J. Bendix, "Discriminating raining from non-raining cloud areas at mid-latitudes using meteosat second generation SEVIRI night-time data," Meteorological Applications, vol. 15, no. 2, pp. 219-230, 2008.

[33] W. Lauer, M. Rafiqpoor, and J. Bendix, Vergleichende Geoökologie der Hochgebirge der nördlichen (Mexiko) und südlichen (Bolivien) Randtropen sowie der inneren Tropen (Ecuador), Abhandlungen der Mathematisch-Naturwissenschaftlichen Klasse, Akademie der Wissenschaften und der Literatur, Mainz, Germany, 2003.

[34] J. Wagemann, B. Thies, R. Rollenbeck, T. Peters, and J. Bendix, "Regionalization of wind-speed data to analyse tree-line wind conditions in the eastern Andes of southern Ecuador," Erdkunde, vol. 69, no. 1, pp. 3-19, 2015.

[35] C. P. K. Basalirwa, "Delineation of Uganda into climatological rainfall zones using the method of principal component analysis," International Journal of Climatology, vol. 15, no. 10, pp. 11611177, 1995.

[36] C. P. K. Basalirwa, J. O. Odiyo, R. J. Mngodo, and E. J. Mpeta, "The climatological regions of Tanzania based on the rainfall characteristics," International Journal of Climatology, vol. 19, no. 1, pp. 69-80, 1999.

[37] G. Poveda, A. Jaramillo, M. M. Gil, N. Quiceno, and R. I. Mantilla, "Seasonality in ENSO-related precipitation, river discharges, soil moisture, and vegetation index in Colombia," Water Resources Research, vol. 37, no. 8, pp. 2169-2178, 2001.

[38] B. Wang, "Climatic regimes of tropical convection and rainfall," Journal of Climate, vol. 7, no. 7, pp. 1109-1118, 1994. 
[39] J. Ronchail, G. Cochonneau, M. Molinier et al., "Interannual rainfall variability in the Amazon basin and sea-surface temperatures in the equatorial Pacific and the tropical Atlantic Oceans," International Journal of Climatology, vol. 22, no. 13, pp. 16631686, 2002.

[40] A. Laraque, J. Ronchail, G. Cochonneau, R. Pombosa, and J. L. Guyot, "Heterogeneous distribution of rainfall and discharge regimes in the Ecuadorian Amazon basin," Journal of Hydrometeorology, vol. 8, no. 6, pp. 1364-1381, 2007. 

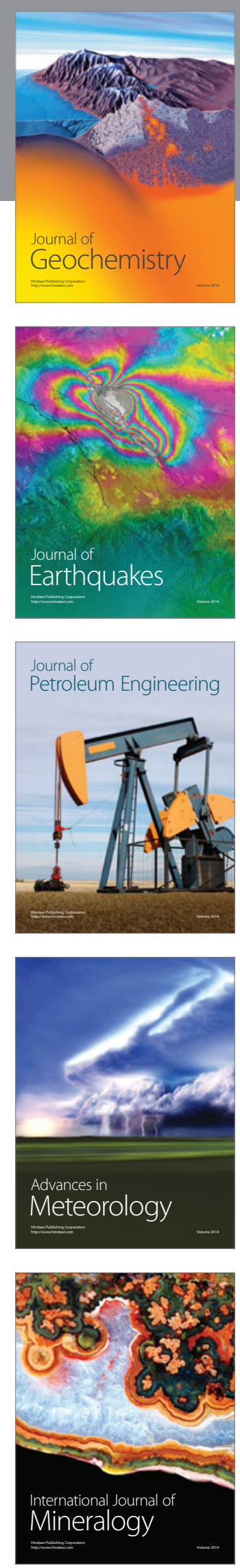
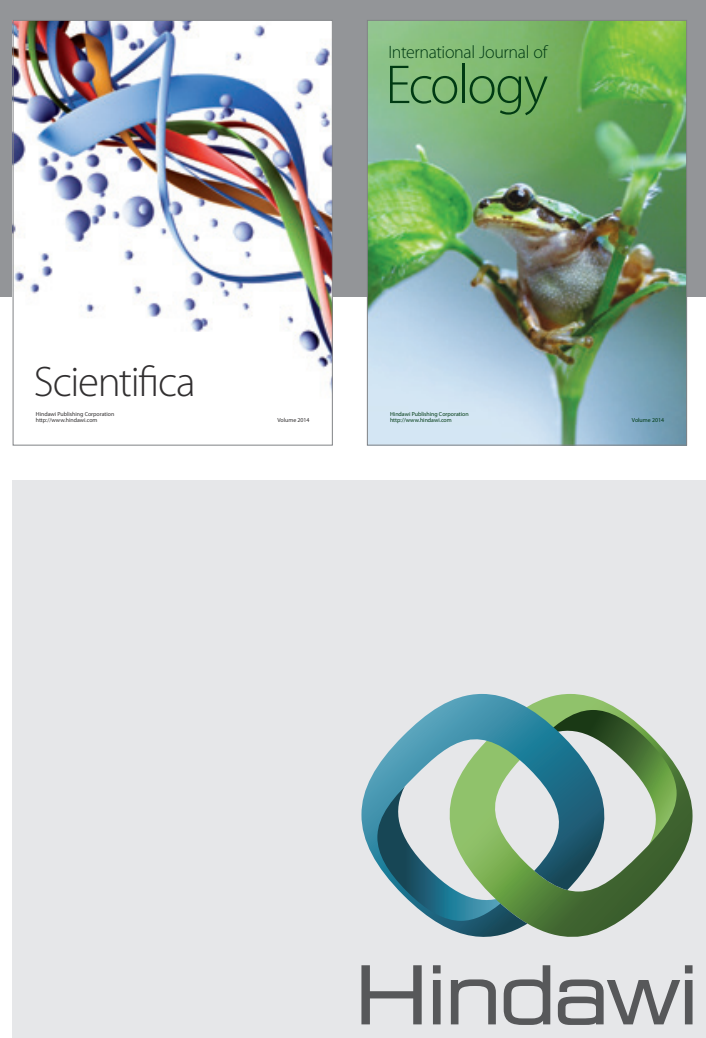

Submit your manuscripts at

http://www.hindawi.com
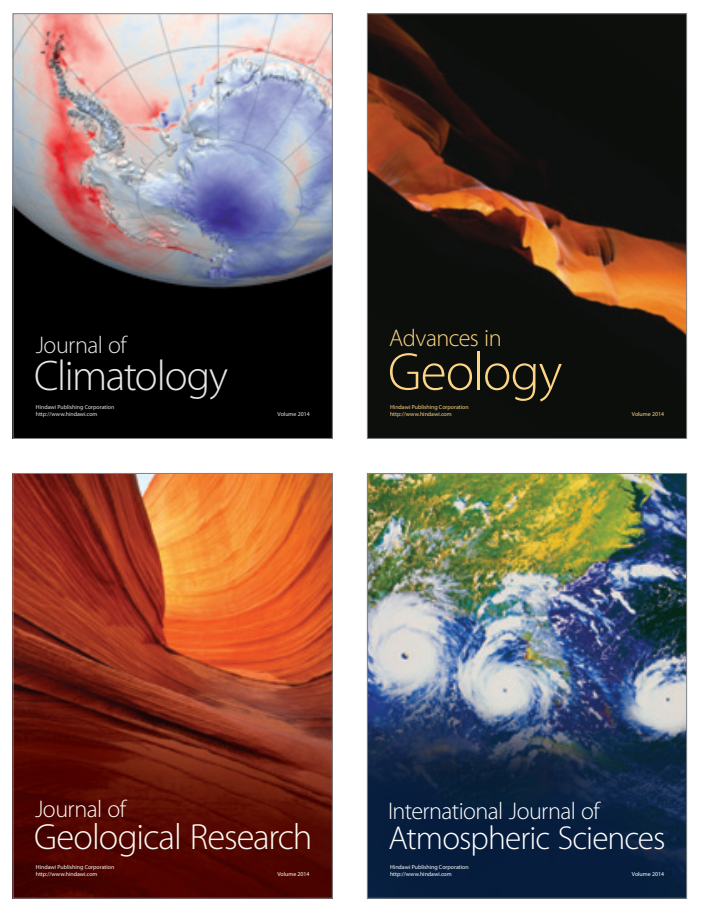

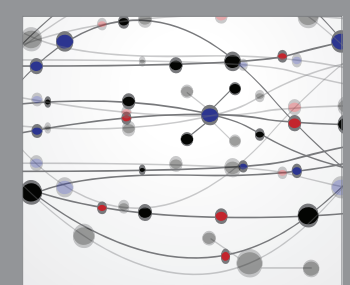

The Scientific

\section{World Journal}
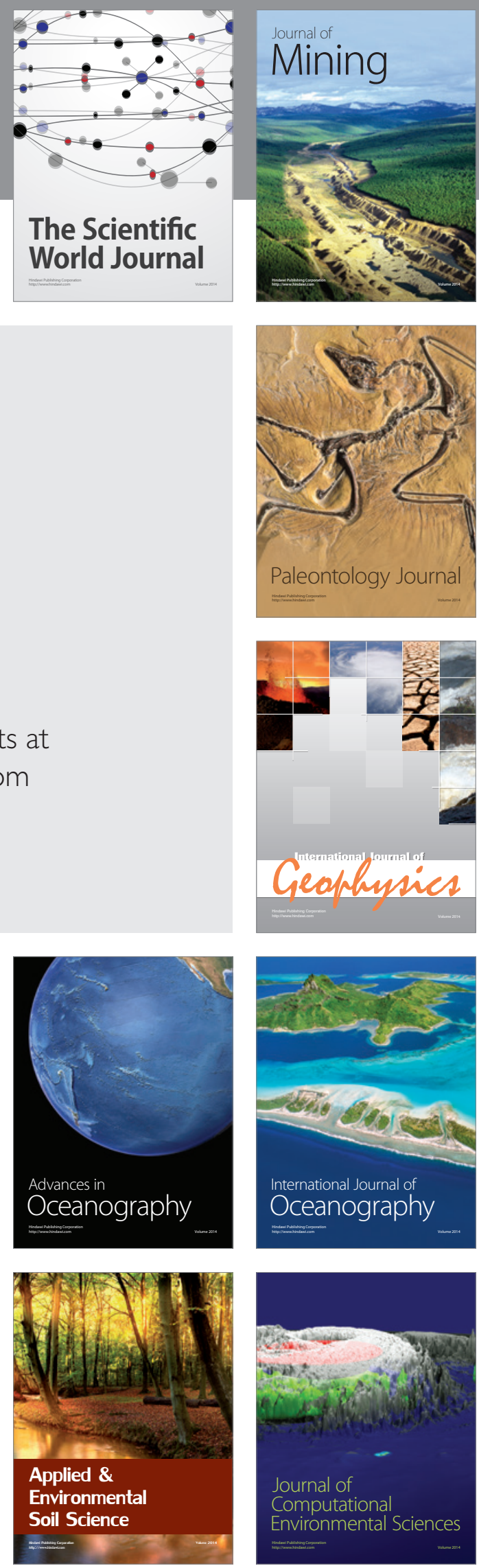